\title{
The Effect of Laminectomy on Spinal Cord Blood Flow, Energy Metabolism and ATPase Activity ${ }^{\star}$
}

\author{
D. K. Anderson, Ph.D. and E. D. Means, M.D. \\ Spinal Cord Injury Laboratory, Cincinnati VA Medical Center and University \\ of Cincinnati College of Medicine, Cincinnati, Ohio 45220, U.S.A.
}

The purpose of these studies was to determine the effects of dorsal laminectomy on spinal cord blood flow (SCBF) energy metabolism, $\mathrm{Na}^{+}-\mathrm{K}^{+}$-adenosine triphosphatase (ATPase) activity and release of arachidonate, a polyunsaturated fatty acid. With the laminectomy site open, SCBF was significantly depressed $(22 \%$ to $45 \%)$ along the entire length of the spinal cord at 15 minutes postlaminectomy. Concurrently, there were significant increases in the tissue levels of the adenine nucleotides adenosine diphosphate (ADP) and adenosine monophosphate (AMP) and a significant decrease in the tissue energy charge. At one hour after laminectomy, SCBF approached control values if the laminectomy site was closed but remained depressed if the incision was left open. Similarly, at 24 hours postlaminectomy SCBF had normalised if the laminectomy site was closed. However, if within the one hour preceding the 24 hour SCBF measurement, the laminectomy site was reopened, SCBF tended to fall at and caudad to the laminectomy site. Other laminectomy induced changes were: (a) a 66 per cent decline in the activity of the plasma membrane bound enzyme $\mathrm{Na}^{+}-\mathrm{K}^{+}-$ ATPase between from 2 to 24 hours after laminectomy and (b) a six-fold increase in spinal cord tissue arachidonate levels by 10 minutes after laminectomy. The partial inhibition of $\mathrm{Na}^{+}-\mathrm{K}^{+}$-ATPase activity by laminectomy was reversed and actually enhanced 1.5 to two-fold if the laminectomy site was capped with methyl methacrylate. Postlaminectomy arachidonate values returned to normal levels by 90 minutes of the laminectomy site was continuously covered with $37^{\circ} \mathrm{C} \mathrm{NaCl}$. These data indicate that laminectomy can cause a significant perturbation in SCBF along with certain tissue biochemical parameters. At the present time, the mechanism(s) for these laminectomy induced changes are unknown although a temperature induced vasoconstriction of spinal cord vessels is suspected. These laminectomy initiated alterations appear to be transient. Cats allowed to recover following laminectomy showed no demonstrable neurological deficit or histologic evidence of tissue damage. Thus, this operative procedure does not appear to permanently affect spinal cord functioning unless, perhaps, there is a pre-existing vascular insufficiency.

(Supported by the Veterans Administration, Cincinnati, $\mathrm{OH}$ )

^Abstractof paper readatthe International Symposium of Spinal Cord Injury, Venice, November, 1983. 